\title{
ROSCAS REMAIN STRONG IN INDIA DESPITE GREATER FINANCIAL INCLUSION
}

\author{
Alka Bramhandkar ${ }^{1}$--- Mary Ellen Zuckerman ${ }^{2}$ \\ ${ }^{\prime}$ Professor of Finance and International Business Park Center for Business and Sustainable Enterprise Ithaca College, \\ Ithaca \\ ${ }^{2}$ Park Center for Business and Sustainable Enterprise Ithaca College, Ithaca
}

\begin{abstract}
We begin this paper by summarizing various studies which used surveys and economic models to describe the characteristics and benefits of the old tradition of ROSCAs which is prevalent in many developing countries around the world. These studies also document the types of draws and the factors that motivate people to participate in a ROSCA. We expand the information on this tradition in a state in India where ROSCA is referred to as bhishi. During the month of January 2013, we interviewed (in-person $\Xi^{2}$ over the telephone) several regular participants living in two metro areas in the State of Maharashtra, namely, Mumbai $\sigma^{\circ}$ Pune. Another smaller city of Miraj was also included. The findings from the interviews in India are illustrative of the creative ways people have taken the old, money-based idea of bhishi and interwoven it with the fabric of social and cultural traditions. It is being kept alive to build and strengthen relationships among friends, relatives, and neighbors. Incorporating the fun dimensions ranging from enjoying different cuisine to taking trips into the old tradition seems to maintain its popularity. This behavior is noteworthy especially with India's recent entry into the world market as an emerging economic power. Although people with lower incomes still value bhishi in its traditional role as a saving vehicle (and occasionally as a lender of last resort), most middle and upper-income earners strongly believe in this modern evolution of an old tradition and are committed to continue it.
\end{abstract}

Keywords: ROSCA, Savings, India, Micro-banking, Micro-finance, Personal finance.

Received: 2 December 2013/ Revised: 23 December 2013/ Accepted: 10 February 2014/ Published: 3 March 2014

\section{INTRODUCTION}

ROSCAs (rotating savings and credit associations) have been around for decades. A ROSCA works like a cooperative organization where members make a commitment to specific responsibilities in return for some privileges and rights. In a ROSCA, each member agrees to 
contribute a fixed amount of money periodically, say weekly or monthly. When the members meet at predetermined times one member is chosen, using the agreed upon method, to receive the contributions made by all the members in that time period. Once a member "wins" his/her share, she is not allowed to get any money for the remaining duration of the association. To accommodate everyone's busy schedule, some groups announce the winner in advance thus eliminating the need for a meeting. This practice is more common with members of the lower income class who participate mainly to save money and may not have the luxury of time to come to a meeting.

ROSCAs' presence has been studied in several developing countries like Egypt, Cameroon, Mexico, Kenya, Gambia, Niger, Bolivia, and Philippines. Repeated attention has been directed by researchers at countries like Jamaica and Taiwan. Taiwan is peculiar since it has also enjoyed tremendous economic growth making the access to traditional financial institutions easier. (Levenson and Besley, 1996; Handa and Kirton, 1999; Anderson et al., 2009). In Japan, a developed industrialized nation, ROSCA is referred to as kou. Interestingly, new immigrants settling in countries like UK and US have continued to use these savings associations in their newly adopted countries. For example, saving habits of Koreans and West Indians in Los Angeles, South Asians in Oxford and Somali women in UK have been analyzed by various researchers to conclude that they remain popular despite the easy access countries like the U.S. and U.K. provide for maintaining saving accounts. (Anderson et al., 2009).

Our paper is organized as follows. We begin with a brief review of the Indian banking system. The next section discusses the major reasons ROSCAs remain popular. After explaining the types of draws, we present a brief overview of ROSCAs in India followed by the literature review. In the section before the conclusion, we summarize the results of our interviews with several participants.

\section{REASONS FOR THE POPULARITY OF ROSCAS}

The reasons for the popularity of ROSCAs can be classified in two main categories, social and financial. Since most of these agreements are not formal or legally enforceable, it is commonly observed that the members come from a particular ethnic group, economic status, gender, work colleagues, or circle of friends who need to interact with each other often outside their ROSCA meetings. These social bonds act as enforcers ensuring that members keep their commitments. It has been noted that many members also enjoy the element of surprise; you may not know when you will "win," satisfying their need to gamble. (Handa and Kirton, 1999). Some members with less inclination to gamble may view these arrangements as "no lose lotteries".

The financial reasons can be traced to both macro and micro economic factors. At the macro level, when capital markets are not perfect, carry high transaction costs for small savings or loans (e.g. need to produce a letter of reference to open a bank account), and availability and access to information is spotty at best, savers and borrowers seek informal, cheaper channels like ROSCAs 
that they can trust. At the individual level, savers use these arrangements as a solution for lack of self-control (Handa and Kirton, 1999; Kovsted and Lyk-Jensen, 1999). Periodic forced contributions enable the participants to buy durable goods, wives to hide money from their husbands and investors to earn higher returns (Levenson and Besley, 1996; Ambec and Treich, 2007). For example, in a bidding type of agreement, if you choose to receive your share last you could earn a higher level of income (usually no taxes are paid) and risk (social pressure to keep the group together with minimal possibility of default) adjusted rate of return normally not available through established financial institutions. A bidding organization may also provide insurance which may not be easily available to most people. Discount or premium bidding ROSCAs offer ways to borrow (if you win early) and save (if you win later) for a specific purpose like education.

\section{TYPES OF DRAWS}

If the ROSCA uses the random draw method, winners are chosen with the lottery technique although exceptions may be made for members in crisis with everyone's agreement. (Handa and Kirton, 1999). Mechanisms used in bidding groups can either use the discount (member offering the highest discount wins but promises to pay the higher fixed amount in future periods) or the premium method (contributions increase over time) (Kovsted and Lyk-Jensen, 1999).

\section{BANKING IN INDIA}

The idea of financial inclusion is catching up with the Indian government as the income levels and the numbers of middle class people are increasing. Several projects have been launched to increase participation in banking. Sharma (2010) describes the ID plan consisting of a "a mix of biometric information - digital photos, fingerprints and iris scans-as well as names, addresses, gender and dates of birth" that the government recruited tech team came up with. Bhargava (2011) reported on the projections made by the Tower Group which states that the mobile bank users will increase from 10 million in 2009 to more than 53 million in 2013. Tyler et al in their 2012 study report that in 2011 only 55 percent of Indians had a deposit account although 81 percent of Indian households do save. Many Indians view bank accounts as mainly for the wealthy with larger amounts of deposits. Poor households save through livestock or informally at home. Banks generally require not only high minimum amounts to open an account but also demand onerous documentation which present high barriers to entry to many people.

In addition, low income households need liquidity and an institution that is open to accepting smaller deposits. Indians value easy access to funds to meet emergency needs since most people do not make a lot of money to live on. Security and return on savings are also important as it is a common practice to lend money to neighbors who offer high rates of return.

"In 2005, the Reserve Bank of India (RBI) compelled banks to offer a basic banking No Frills Account either with zero or very low minimum balance in order to attract low-income households." (Tyler et al., 2012). As of March 2012, banks had covered 74,199 villages, or 99.7 
percent of the target assigned to them. Two years earlier, banks had 21, 475 branches in rural areas, but by March 2012, they provided banking services in rural areas through "138502 outlets, comprising 24,085 rural branches, 111,948 BC outlets and 2,469 outlets through other modes" such as ATM's and mobile vans" (Tyler et al., 2012). Another notable statistic is the increase in the number of banks in the international ranking of the top 500 banks. From just six banks in 2007 the number had increased to 20 by 2010. (Master, 2012). Another significant development is evident in the number of applications India's central bank has received from the largest companies like Tata Sons and Aditya Birla Nuvo Ltd which are conglomerates with interests across a wide variety of industries to enter the financial services field. (Acharya, 2013).

\section{ROSCAS IN INDIA}

India presents a unique situation in which the country has experienced significant economic prosperity in the last two decades with the availability of banks, credit cards and ATMs growing exponentially. Table I presents data on the number and types of Indian banks. In the major industrial state of Maharashtra with Mumbai as its state capital as well as the financial capital of India, ROSCAs are called bhishis. If the monthly meetings (most common frequency) are held in restaurants, they are referred to as kitty parties. Even though the major purpose of the meeting is to announce a winner, it is not uncommon to find several social aspects woven through these group meetings. Depending on the member preferences, some groups may play cards, discuss a pre-assigned book, or engage in singing movie or religious songs in a group. Recently, a few groups with more wealthy members have taken up social causes. These groups, instead of giving the money collected to group members, donate the money to a particular social cause voted on by the members. Senior citizens find bhishis a good excuse to meet friends and family on a regular basis. Some members welcome the opportunity to make new friends through existing relationships. Hosts are also known to show off their culinary skills by preparing food for the monthly meeting.

It appears that bhishis are popular among all income groups. The monthly contribution can range from as low as Rs. 50 to as high as Rs, 10,000. (Ambec and Treich, 2007). Although the majority of the members are women it is not uncommon to find men participating as well. In addition, they are embraced by professionals, household help, spouses of wealthy individuals cutting across different education levels and castes.

\section{LITERATURE REVIEW}

Several economic models have been proposed to explain the persistence of ROSCAs across many geographic regions. Anderson et al. (2009) explore two motives related to the success of the group and conclude that the informal groups can continue successfully only if the cost of being a social outcast is really high. They also illustrate their findings using 1997 survey results gathered from the Nairobi slums. Handa and Kirton (1999) continue with the idea of organizational 
structure and use Jamaican data from 1994 to show that payments to leaders of the ROSCAs ensure their success and longevity. Kovsted and Lyk-Jensen (1999) focus on the type of ROSCA preferred by the members. They show that the market data on cost of obtaining a loan and rate of return members could earn on their savings externally determine the type of ROSCA (discount or premium bidding) members would prefer. Their study did not extend the analysis to any actual data. Ambec and Treich (2007) address one of the major reasons for participating in an informal group i.e. the self-control issue. Participants who believe that they cannot, on their own, set aside a fixed amount at set time period on a regular basis because they lack self discipline may sign up for fixed monthly contributions that these groups demand. The authors propose a model to show that people view a ROSCA as a commitment device to help them to reduce the level of current disposable income minimizing the possibility of buying unnecessary goods and services. A 1996 study by Levenson \& Besley is based on the data from Taiwan during the years 1977-1991. They conclude that the failure of the regular financial institutions leads to an unexpected finding of increase in participation rates with rising income. (Ambec and Treich, 2007). They also mention that other factors such as tax avoidance may play an important role in the high participation rates.

\section{OUR STUDY}

The next stage of our study took place in India in January 2013. India presents a unique perspective on ROSCAs. Over the last two decades, its economy has grown by leaps and bounds with widespread availability of banking services. Over a four year period ending in 2011, the number of banks has grown by $24.68 \%$ (Table I) whereas the population growth has slowed to $5.25 \%$ ( http://www.indexmundi.com/g/g.aspx?c=in). Bhishis remain popular despite the higher job participation rates by women. We identified a sample of participants across various classes of the society. We designed a questionnaire soliciting basic information on characteristics like age, education, gender, and income, to create a profile of Indian bhishi participants. We conducted one-on-one interviews with the participants asking them questions about their own motivations exploring both social and financial benefits of bhishis.

Table-1. Banking in India

\begin{tabular}{lrrr}
\hline Type of Bank & $\mathbf{2 0 0 7}$ & $\mathbf{2 0 1 1}$ & \% change \\
\hline Public Sector Banks & 52088 & 64673 & 24.16 \\
\hline Private Sector Banks & 7424 & 12001 & 61.65 \\
\hline Foreign Banks & 272 & 319 & 17.28 \\
\hline Regional Rural Banks & 14822 & 16034 & 8.18 \\
\hline Miscellaneous & 47 & 53 & 12.77 \\
\hline All Commercial Banks & 74653 & 93080 & 24.68 \\
\hline
\end{tabular}

Notes: 1. Data is as per information reported by banks.

2. \$ Includes IDBI Bank Ltd.

3. Data on number of offices include administrative offices.

Source: Master Office File (latest updated version) on commercial banks, Department of Statistics and Information Management, RBI 
Twenty individuals were interviewed in detail either in person or over the phone during the month of January 2013. A summary of their major characteristics is shown in Table II.

Table-2. Characteristics of the Participants

\begin{tabular}{lrrrr}
\hline & Average & Low & \multicolumn{2}{c}{ High } \\
\hline Age & 55 & 25 & \multicolumn{1}{c}{75} \\
\hline Income (OOOs) & 24.5 & 8 & 100 & \\
\hline Contribution & 1200 & 50 & Bachelor's & $>$ Master's \\
\hline & none-7th grade & $8-11$ th grade & 3 & 5 \\
\hline Education & 6 & 6 & & \\
\hline
\end{tabular}

The youngest person was 25 and the oldest person was 75 . Eighteen out of 20 individuals interviewed were women. All interviewees live in the State of Maharashtra. The education levels of the bhishi participants covered a wide range. The person with the lowest level of education had quit school after the second grade whereas one person holds a $\mathrm{Ph} \mathrm{D}$ in chemistry and another is a pediatrician. Despite the differences, some common themes that emerged are quite interesting. Not a single individual was concerned about fraud or lack of trust among the members. Perhaps the trust may be due to the presence of elders in a group who are traditionally and universally respected for their life experiences regardless of their other skills or education. Also, avoidance of tax did not cross their minds. Almost all interviewees took a strong objection when we used the word "playing" bhishi. They did not like the implication that we may be referring to an element of gambling which actually does not exist in the type of bhishi played. There is also a very high level of cooperation. If a particular member needs the money and does not win during that month, it is quite common for the winner to turn over the total amount to the needy person. Also, the decision about the host is based on whether a particular member has any other obligations making it difficult for them to host the event. Some bhishis came to an end naturally just like friendships come to an end. There was no set number of years a particular bhishi went on. Their lives were unique to the needs of the group. For example, a bhish $i$ started by mother-in-laws for over quarter of a century ago is now continued by their daughter-in-laws who live in the same city. Based on the responses collected, it is quite evident that bhishi remains popular at various income levels \& castes as well as professions despite the current explosion in the number of banks and the variety of services offered by these banks. Besides the standard method of participating by pledging to contribute money on a monthly basis, some interesting variations were observed. These are presented in Table III.

Table-3. Types of Bhishi

\begin{tabular}{c}
\hline Basic-pure savings \\
Basic- savings plus social \\
Book \\
Gold \\
Family Reunion \\
Fund \\
Travel \\
Family
\end{tabular}


Participants who work as household help and earn less money do not meet and only the winner shows up at the leader's place to collect the money. On the other hand, most middle income earners not only meet every month but also incorporate some social aspects such as food and music to each meeting. Some of these are:

1. Book (pustak) bhishi

The participants in this type of bhishi use their monthly contributions to buy books, circulate them among members, and return them to the winner. In this case, the winner ends up with books instead of money.

2. Gold bhishi (Suvarna Sanchay Yojana)

This type of bhishi is not run among friends and relatives. It is a technique used by jewelry stores to raise short term working capital. Usually, the store collects a monthly contribution equal to about one gram of gold (prices determined in the world market). At the end of 10-11 months, the participant is given gold equal to the amount contributed plus additional one-two grams. Depending on the store, contributions as well as the amount of gold received could be based on the gold price on the date of contribution and/or the date of final gold distribution. Traditionally, jewelry transactions are based on trust. An individual will stay with the same jeweler his/her family may have used for several decades. Indians, at all income levels, accumulate gold not only for their own use and to store wealth but also to ensure that gold is given to their daughters as their wedding gifts. The total amount of gold given is based on one's income. Some recent variations to this practice include silver and diamond bhishis which work just like the gold bhishi. In this arrangement, since there are no monthly drawings or rotating winners, perhaps it may be best to rename it as an OSCA.

3. Family Reunion Bhishi

This type of bhishi is used to ensure that the extended family members get together every six months for a weekend in a structured manner. The winner from the previous meeting coordinates and hosts the get-together and receives the total amount contributed. The gathering begins on a Saturday morning and the day is spent playing games, taking a sightseeing trip as well as enjoying good food. Over Sunday lunch, each participant is required to stand up and share unique memories of any other participant. This sharing of observations allows members of the younger generation to get to know the members of the older generations and begin establishing strong bonds with the members of their own generation.

4. Fund Bhishi

Fund bhishi is different from all other bhishis in the sense it takes over the multiple roles of a mutual fund (contributions can be unequal), a lender (give out loans to needy members) and a money manager (make decisions about where \& how to invest the money). Two to three members take on the responsibility of opening a bank account and 
keeping track of deposits, loans and disbursements. Loans are granted to needy members and interest earned on loans is shared by all. In January 2013, the interest rate on loans made by one fund bhishi was 3\% per month. Any income generated is distributed to the members in proportion of their ownership. If a borrower defaults on a loan, the person who introduced the borrower to the group is held responsible for the repayment regardless of the reason for default.

5. Family Bhishi

This type of bhishi is more prevalent in the middle to upper middle income groups. In this case, the whole family including children participates. Again, the focus of this bhishi is to ensure frequent interactions among various families.

6. Foreign/domestic trip Bhishi

In this case, monthly contributions continue (no winners are announced) until a large sum sufficient to pay for everyone's trip to a nice domestic/foreign destination is accumulated. All decisions are made by the members in a group in a co-operative fashion.

The reasons for participation can be easily divided into distinct groups based on the income levels. For people earning less than Rs 10,000 a month the following list of reasons emerged:

1. Even though it is possible (it does require a lot more paperwork compared to the U. S.) to open a bank account, they do not have time to go to a bank to make deposits or withdrawals due to their long work hours. Using the internet to do banking is completely out of the question as they cannot afford to buy a computer or to subscribe to a monthly service. Bhishi contributions can be dropped off at any hour and at their convenience.

2. It is difficult for them to have the discipline to set aside same amount on a monthly basis. Most of them make barely enough to pay for their expenses. Bhishi contributions are viewed as mandatory and payments are never missed due to the social taboo/pressure imposed on them if a deposit is not made in a timely manner (there is a short grace period allowed). Few interviewees stated that they have sometimes resorted to borrowing to be able to make a contribution by the due date.

3. Overwhelming majority of the participants stated that they used the "winning" to buy gold jewelry. A distant second was household appliances like a food processor. Paying off debt and paying for a wedding were also mentioned as some of the uses of the winning.

For most middle to upper income participants saving money was not a major reason. For all of them the social aspects of regular meetings with friends and family were the predominant factor in their decision to join a group. Below is a list of the frequently mentioned reasons:

1. Have a guilt free designated time for self away from in-laws, children \& husbands.

2. Engage in- 
- Chit-chat to get an update on each other's family members and friends

- Enjoy good food

- Exchange recipes

3. One group started meeting with residents of a big co-op building they live in. They found that with the hectic pace of life in a major metro city, neighbors did not get a chance to see other neighbors. They used these meetings not only to get to know each other but also to discuss any building related issues and come up with a list for submission to the Board for action.

4. Go on a picnic or an overnight trip with friends.

5. Even though buying jewelry with the winnings was mentioned as the most common use, other unique ways were also stated.

- Pay for medical bills of household help

- Make a charitable contribution

- Just set aside the money over which they are the only ones with control.

\section{CONCLUSIONS}

We begin this paper by summarizing various studies which used surveys and economic models to describe the characteristics and benefits of the old tradition of ROSCAs which is prevalent in many developing countries around the world. These studies also document the types of draws and the factors that motivate people to participate in them. We expand the information on this tradition in a state in India where ROSCA is referred to as bhishi. During the month of January 2013, we interviewed (in-person \& over the telephone) several regular participants living in two metro areas in the State of Maharashtra, namely, Mumbai \& Pune. Another smaller city of Miraj was also included. The findings from the interviews in India are illustrative of the creative ways people have taken the old, money-based idea of bhishi and interwoven it with the fabric of social and cultural traditions. It is being kept alive to build and strengthen relationships among friends, relatives, and neighbors. Incorporating the fun dimensions ranging from enjoying different cuisine to taking trips into the old tradition seems to maintain its popularity. This behavior is noteworthy especially with India’s recent entry into the world market as an emerging economic power. Although people with lower incomes still value bhishi in its traditional role as a saving vehicle (and occasionally as a lender of last resort), most middle and upper-income earners strongly believe in this modern evolution of an old tradition and are committed to continue it. Of course, only time will tell if it survives the rapid economic, social and cultural changes Indian society is experiencing. 


\section{REFERENCES}

Acharya, N., 2013. Firms seek India bank permits. The Wall Street Journal. New York, NY, July 2. Pg. C 3.

Ambec, S. and N. Treich, 2007. Roscas as financial agreements to cope with self-control problems. Journal of Development Economics, 82(1): 120-137.

Anderson, S., J. Baland and K. O. Moene, 2009. Enforcement in informal savings groups. Journal of Development Economics, 90(1): 14-23.

Bhargava, M., 2011. Leapfrogging from e-banking to m-banking, Financial Express, New Delhi, India.

Handa, S. and C. Kirton, 1999. The economics of rotating savings and credit associations: Evidence from the Jamaican 'Partner'. Journal of Development Economics, 60(1): 173-194. Available from http://www.indexmundi.com/g/g.aspx?c=in.

Kovsted, J. and P. Lyk-Jensen, 1999. Rotating savings and credit associations: The choice between random and bidding allocation of funds. Journal of Development Economics, 60(1): 143-172.

Levenson, A. and T. Besley, 1996. The anatomy of an informal financial market: Rosca participation in Taiwan. Journal of Development Economics, 51(1): 45-68.

Master, A., 2012. Looking forward, looking back, business today. Available from http://businesstoday.intoday.in/story/best-banks-2012-indian-bankingchallenges/1/189858.html.

Sharma, A., 2010. India embarks on project to ID 1.2 billion people. The Wall Street Journal, New York, NY, Pg. A 1 .

Tyler, E., A. Ravi, S. Bhat, M. Ramji and A. Ballem, 2012. From social banking to financial inclusion. Available from http://www.newamerica.net/sites/newamerica.net/files/policydocs/From_Social_Banking_to_Fi nancial_Inclusion_2012.pdf. 